\title{
Core fueling of DEMO by direct line injection of high-speed pellets from the HFS
}

\author{
Antonio Frattolillo, Larry R. Baylor, Francesca Bombarda, Stephen K. Combs, Christian Day, \\ Peter T. Lang, Silvio Migliori, Bernard Pégourié, Bernhard Ploeckl
}

\begin{abstract}
Pellet injection represents to date the most realistic candidate technology for core fueling of a DEMO tokamak fusion reactor. Modelling of both pellet penetration and fuel deposition profiles, for different injection locations, indicates that effective core fuelling can be achieved launching pellets from the inboard high field side at speeds not less than $\sim 1 \mathrm{~km} / \mathrm{s}$. Inboard pellet fueling is commonly achieved in present tokamaks, using curved guide tubes; however, this technology might be hampered at velocities $\geq 1 \mathrm{~km} / \mathrm{s}$. An innovative approach, aimed at identifying suitable inboard "direct line" paths, to inject high-speed pellets (in the 3 to $4 \mathrm{~km} / \mathrm{s}$ range), has been recently proposed as a potential complementary solution. The fuel deposition profiles achievable by this approach have been explored using the HPI2 simulation code. The results presented here show that there are possible geometrical schemes providing good fueling performance. The problem of neutron flux in a direct line of sight injection path is being investigated, though preliminary analyses indicate that, perhaps, this is not a serious problem. The identification and integration of straight injection paths suitably tilted may be a rather difficult task, due to the many constraints and to interference with existing structures. The suitability of straight guide tubes to reduce the scatter cone of high-speed pellets, is therefore of main interest. A preliminary investigation, aimed at addressing these technological issues, has been recently started. A possible implementation plan, using an existing ENEAORNL facility is shortly outlined.
\end{abstract}

Index Terms-DEMO tokamak fusion reactor, HFS highspeed pellet injection, straight guide tubes

Manuscript received June 2017. This work has been carried out within the framework of the EUROfusion Consortium and has received funding from the Euratom research and training programme 2014-2018 under grant agreement No 633053. The views and opinions expressed herein do not necessarily reflect those of the European Commission.

A. Frattolillo, F. Bombarda and S. Migliori are with the Italian National Agency for New Technologies, Energy and sustainable Economic Development (ENEA), C. R. Frascati, 00044 Frascati (Rome), Italy (e-mail: antonio.frattolillo@enea.it,

silvio.migliori@enea.it)

L. R. Baylor and S.K Combs are with the Oak Ridge National Laboratory (ORNL), Oak Ridge (TN), 37831 USA (e-mail: baylorlr@ornl.gov, combssk@ornl.gov)

C. Day is at Karlsruhe Institute of Technology (KIT), 76021 Karlsruhe, Germany, (e-mail: christian.day@kit.edu)

P.T. Lang and B. Ploeckl are with Max Planck Institute for Plasma Physics, 85748 Garching, Germany (e-mail: ptl@rzg.mpg.de, brp@ipp.mpg.de)

B. Pégourié is with CEA-IRFM, 13108 Saint-Paul-lez-Durance, France (email: bernard.pegourie@cea.fr)

\section{INTRODUCTION}

CORE fuelling of a DEMO tokamak fusion reactor is under investigation within the EUROfusion Work Package

"Tritium, Fuelling and Vacuum" (WP-TFV). Extensive analyses of DEMO fuelling requirements and of related fuelling technologies presently available, indicate that pellet injection still represents, to date, the most realistic option. In general, the fuel deposition depth inside the plasma depends on two distinct phenomena, i.e. the pellet penetration that, for given target plasma profiles, is determined by the pellet mass and by its injection velocity, followed by a drift of the locally ablated material in the direction opposite to the gradient of the magnetic field. The physics of pellet fuelling of future tokamak fusion reactors, where the fuel deposition depth is strongly dominated by the $\nabla \mathrm{B}$-induced displacement, differs from that of present day machines, where the pellet penetration is typically larger than the drift effect, and may still play an important role [1].

Modelling of both pellet penetration and fuel deposition profiles for different injection locations, for specific DEMO plasma reference scenarios and assuming the ITER reference pellet mass $\left(6 \times 10^{21}\right.$ atoms), indicates indeed that the pellet penetration is always very shallow, almost regardless of the pellet speed, and does not contribute to fuel deposition depth. Consequently, injection from the Low Field Side (LFS), where the $\nabla \mathrm{B}$ is unfavourable, is inadequate, whereas effective core fuelling can be achieved launching pellets from the High Field Side (HFS) at speeds $\geq \sim 1 \mathrm{~km} / \mathrm{s}$. These speeds are necessary to ensure that pellets are ablated underneath the plasma pedestal, where the drift effect can contribute to improve the fuel deposition depth [2]. Vertical injection may be effective only if pellets are injected at relatively higher speed from a radial position $\leq \sim 8 \mathrm{~m}$ from the axis of the reactor; this distance, however, depends on specific plasma scenarios. HFS pellet fuelling is commonly achieved, in present tokamaks, using curved guide tubes; however, this technology might be hampered at velocities $\geq 1 \mathrm{~km} / \mathrm{s}$. We recently proposed, as a potential complementary solution, an innovative approach, aimed at identifying suitable inboard "direct line" paths to inject high-speed pellets from the HFS [3]. This proposal is presently undergoing preliminary investigation. The fuel deposition profiles that can be achieved by this approach are being explored using the HPI2 pellet ablation-deposition code [4],[5],[6]. Some preliminary simulations have been carried out, showing that, within the speed limits attainable by present technologies, there are possible geometrical schemes for direct 
line injection providing good fueling performance, comparable to those achievable with curved guide tubes. Details are given in Section II.

The identification and integration of oblique straight injection paths may be a rather difficult task, due to the many constraints and to interference with existing structures, including the breeding blanket (BB). Therefore, options using the upper vertical port will be explored first, as this represents the simplest approach. In the perspective of a direct line injection of pellets from the HFS, the angular scatter of freeflight high-speed pellets, and/or the suitability of straight guide tubes to reduce the scatter cone and the corresponding open cross section on BB penetration, are of main interest. A new task has been recently proposed within the WP-TFV, aimed at solving these technological issues, using an existing ENEA/ORNL two-stage pneumatic $\mathrm{D}_{2}$ pellet injector; a preliminary implementation plan has been proposed, and is outlined in sections III and IV.

\section{SiMULATED FUEL DEPOSITION OF HIGH-SPEED PELLETS INJECTED THROUGH “DIRECT LINE” GUIDE TUBES}

The capability of fuelling DEMO with high speed pellets injected by "direct line" guide tubes has been investigated through simulations with the pellet ablation-deposition code HPI2. This latter - which is valid for any magnetic and plasma configuration - computes the pellet ablation taking into account thermal ions and electrons, as well as supra-thermal ions generated by the plasma heating systems [4]. The drift model is based on the compensation of the cloud polarization by parallel currents [6]. An additional effect is the pre-cooling of the plasma by the previously ablated material drifting in front of the pellet in the case of HFS injection. A pellet particle content identical to that of the ITER pellets $\left(N_{p}=\right.$ $6 \times 10^{21}$ atoms), and injection velocities $V_{i n j}$ ranging from 2 $\mathrm{km} / \mathrm{s}$ up to $4.5 \mathrm{~km} / \mathrm{s}$, have been assumed. Calculations have been carried out in the EU DEMO1 2015 configuration [7], with major and minor radii $R=9.1 \mathrm{~m}$ and $a=2.9 \mathrm{~m}$, on-axis magnetic field $B=5.7 \mathrm{~T}$, current $I_{p}=19.6 \mathrm{MA}$, average density and electron temperature $\left\langle n_{e}\right\rangle=8 \times 10^{19} \mathrm{~m}^{-3}$ and $\left\langle T_{e}\right\rangle$ $=13.1 \mathrm{keV}$ and pedestal parameters $n_{\text {ped }} \sim 6.5 \times 10^{19} \mathrm{~m}^{-3}$ and $T_{p e d} \sim 5.5 \mathrm{keV}$.

Injection is assumed to be performed from the high field side, either obliquely, with the constraint that every trajectory must pass through the point of coordinates $R_{0}=4.76 \mathrm{~m} ; Z_{0}=$ $7.16 \mathrm{~m}$ to avoid any interference with the Central Solenoid, or vertically through a port of the machine, as shown in Fig. 1(a). For each injection configuration, the resulting deposition profile is characterized by:

- The radius of the deposition profile at its maximum (corresponding to the maximum of density increment $\left.\delta n_{e}\right): \rho_{\max }$.

- The inboard and outboard radii at $1 / 10$ of the maximum deposition: $\rho_{\text {int }}$ and $\rho_{\text {out }}$.

- The fuelling efficiency $\varepsilon_{f}=\frac{4 \pi^{2} R a^{2}}{N_{p}} \int \rho \delta n_{e} d \rho$, where $\rho$ is the normalized minor radius.

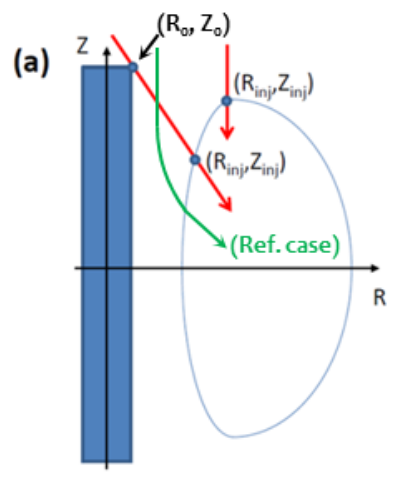

(b) $\delta n_{0}$

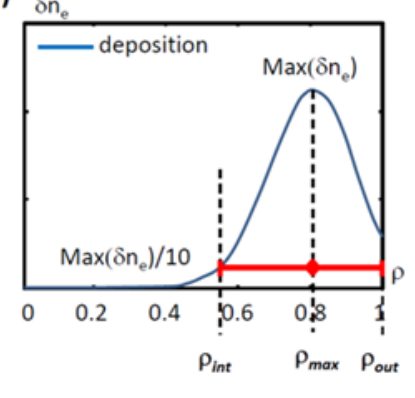

Fig. 1. (a) Schematics of the injection geometries, showing both the reference case (green curve) and straight trajectories identified by $\left(R_{0}, Z_{0}, R_{i n j}, Z_{i n j}\right)$, and (b) the deposition profile characteristics $\left(\rho_{\max }-\right.$ red plain diamonds, $\left[\rho_{\text {int }}, \rho_{\text {out }}\right]$ -red bar)

This definition of $\varepsilon_{f}$, however, takes into account only the effect of the $\nabla B$-induced drift, and not that of an ELM possibly triggered by the pellet. Therefore, the corresponding value has to be considered only as an upper bound.

These different quantities are explained in Fig. 1(b), and summarized in Table I for all the injection geometries considered. They are compared with the corresponding values obtained in the reference conventional configuration, analogous to that described in [1], (i.e. injection from the HFS through a guide tube with a curvature radius of $6 \mathrm{~m}$, and a speed $V_{i n j}=1300 \mathrm{~m} / \mathrm{s}$ ).

TABLE I

INJECTION PARAMETERS AND DEPOSITION PROFILES CHARACTERISTICS FOR THE REFERENCE INJECTION CASE (CURVED GUIDE TUBE) AND HIGH-SPEED PELLETS INJECTED OBLIQUELY OR VERTICALLY THROUGH "DIRECT LINE" PATHS.

\begin{tabular}{|c|c|c|c|c|c|}
\hline \multicolumn{6}{|c|}{ Reference Case (Curved guide tube $; V_{i n j}=1300 \mathrm{~m} / \mathrm{s}$ ) } \\
\hline$Z_{i n j}[\mathrm{~m}]$ & $R_{i n j}[\mathrm{~m}]$ & $\rho_{i n t}$ & $\rho_{\max }$ & $\rho_{o u t}$ & $\varepsilon_{f}$ \\
\hline 1.0 & 6.16 & 0.66 & 0.78 & 0.92 & 0.94 \\
\hline \multicolumn{6}{|c|}{ Oblique HFS injection $\left(V_{i n j}=3000 \mathrm{~m} / \mathrm{s}\right)$} \\
\hline$Z_{i n j}[\mathrm{~m}]$ & $R_{i n j}[\mathrm{~m}]$ & $\rho_{i n t}$ & $\rho_{\max }$ & $\rho_{o u t}$ & $\varepsilon_{f}$ \\
\hline 0.5243 & 6.147 & 0.70 & 0.79 & 0.90 & 0.95 \\
\hline 2.0100 & 6.220 & 0.60 & 0.79 & 1.00 & 0.95 \\
\hline 3.4065 & 6.553 & 0.58 & 0.83 & 1.00 & 0.93 \\
\hline 4.3300 & 7.036 & 0.82 & 0.90 & 0.98 & 0.93 \\
\hline \multicolumn{6}{|c|}{ Vertical injection $\left(V_{i n j}=3000 \mathrm{~m} / \mathrm{s}\right)$} \\
\hline$Z_{i n j}[\mathrm{~m}]$ & $R_{i n j}[\mathrm{~m}]$ & $\rho_{i n t}$ & $\rho_{\max }$ & $\rho_{o u t}$ & $\varepsilon_{f}$ \\
\hline 3.4065 & 6.553 & 0.63 & 0.86 & 1.00 & 0.92 \\
\hline 4.3300 & 7.036 & 0.61 & 0.85 & 1.00 & 0.92 \\
\hline \multicolumn{6}{|c|}{$V_{i n j}$ scaling $\left(R_{i n j}=6.22 \mathrm{~m} ; Z_{i n j}=2.01 \mathrm{~m}\right)$} \\
\hline$V_{i n j}[\mathrm{~m} / \mathrm{s}]$ & $\rho_{\text {int }}$ & & & $u t$ & $\varepsilon f$ \\
\hline 2000 & 0.63 & & & & 0.94 \\
\hline 3000 & 0.60 & & & 0 & 0.95 \\
\hline 4500 & 0.60 & & & 9 & 0.95 \\
\hline
\end{tabular}

Simulation results are summarized in Fig. 2: the different geometries of the oblique and vertical injection lines are shown respectively in Figs. 2(a) and 2(c), whereas the 
characteristics of the corresponding deposition profiles are illustrated in Figs. 2(b) and 2(d). Red diamonds represent $\rho_{\max }$, red bars correspond to the interval $\left[\rho_{\text {int }} ; \rho_{\text {out }}\right]$, the blue line and shadowed zone show, for comparison, the corresponding values for the reference case using a curved guide tube. For oblique HFS injection, solutions with performance comparable to that of the reference case can be found for $Z_{i n j} \leq 2.5 \mathrm{~m}$. For larger values of $Z_{i n j}$, the fuel effective deposition decreases significantly. This result is not surprising. In the case of DEMO, indeed, the penetration of pellets (if injected at speeds attainable with present technologies) is predicted to be very shallow, regardless of the injection location and/or of the fact that the pellet trajectory either points toward the plasma centre or not, whereas the effects of the $\nabla \mathrm{B}$-induced drift (which is directed horizontally from the HFS to the LFS) clearly depend on the injection position. In the case of oblique HFS injection with relatively small values of $Z_{i n j}$, this displacement is directed almost perpendicularly to the magnetic flux surfaces, and contributes to improve the fuel deposition depth significantly, while for large values of $Z_{i n}$, it is nearly tangential to the flux surfaces, resulting in a rather marginal fuel deposition, consistent with the relatively peripheral deposition obtained with vertical injections (Fig. 2(d)).

The injection points for the two upper oblique configurations and for the two vertical configurations are identical (points joined by vertical dashed lines in Figs. 2(b) and 2(d)). The differences in the deposition characteristics for the same launching location reflect the sensitivity to the injection angle. (a)

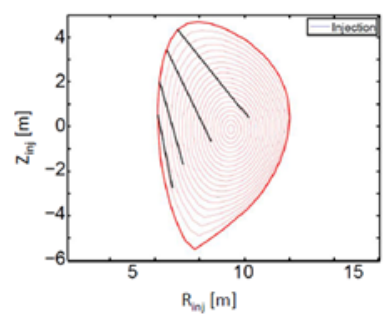

(c)

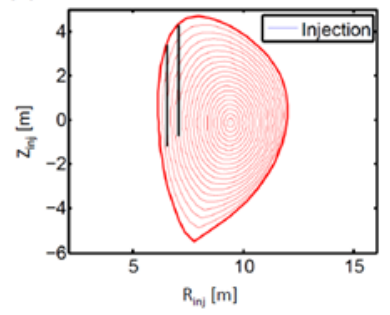

(b)

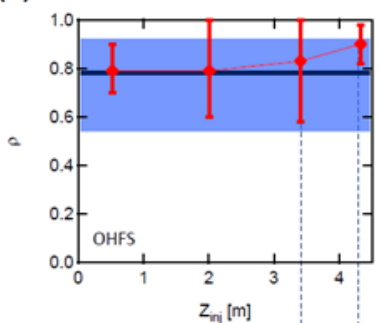

(d)

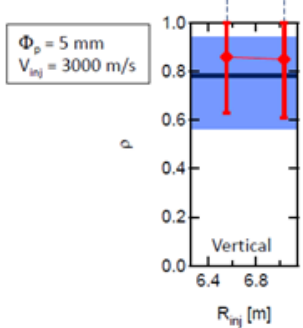

Fig. 2. (a) Oblique HFS "direct line" paths for high-speed pellets; (b) characteristics of the corresponding deposition profiles (red bars and diamonds are explicated in Fig. 1, the blue horizontal line and shadowed zone are the corresponding values for the reference case with a curved guide tube). (c), (d) same as (a), (b) for the vertical "direct line" paths

From the above results, it follows that the optimal configuration is obtained for oblique injection with $Z_{i n j} \sim 2 \mathrm{~m}$ (corresponding to the smallest values of $\rho_{\max }$ and $\rho_{\text {int }}$ ). A scan in pellet velocity has been performed for this launching geometry; the results, shown in Fig. 3, indicate that the gain

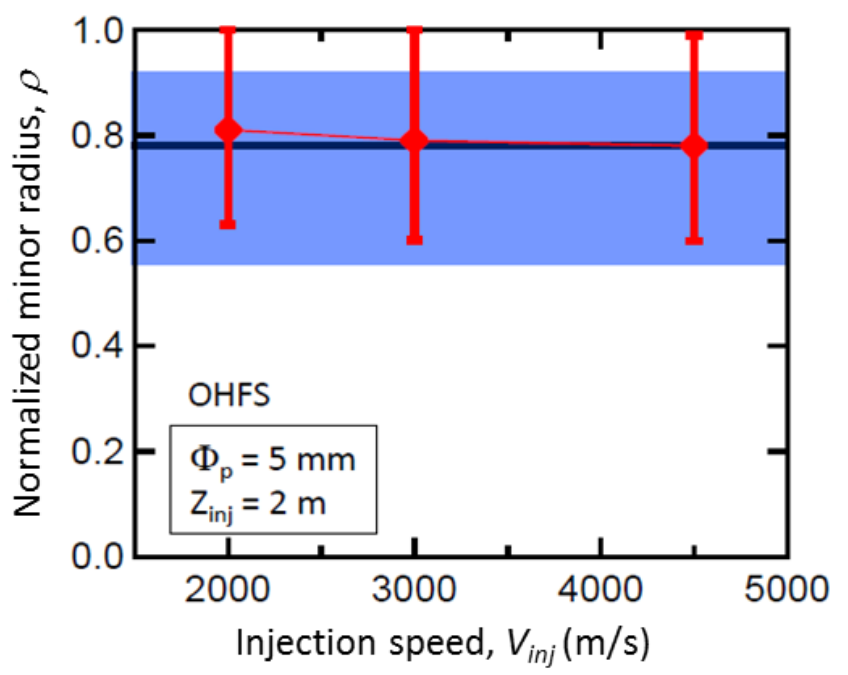

Fig. 3. Characteristics of the deposition profiles as a function of $V_{i n j}$ for the standard oblique HFS (OHFS) launching geometry $\left(R_{i n j}=6.22 m ; Z_{i n j}=2.01 \mathrm{~m}\right)$

obtained by increasing $V_{i n j}$ is only marginal, the asymptotic value of $\rho_{\max }$ and $\rho_{\text {int }}$ being reached as soon as $V_{i n j} \sim 3000 \mathrm{~m} / \mathrm{s}$.

Strictly speaking, the results described above refer only to the EU DEMO1 2015 design. However, as explained in [1], characteristics of pellet deposition are very robust with respect to reasonable changes in the geometry and plasma parameters, and the main conclusions drawn here are expected to remain valid even for future evolutions of the DEMO design.

\section{THE ENEA-ORNL HIGH-SPEED PELLET INJECTOR}

The technology of the two-stage pneumatic light-gas guns (TSG) is well proven, and represents to date the most realistic option for the injection of high-speed cryogenic fuel pellets in fusion machines. The ENEA Frascati team has been at the forefront in the development of high-speed pellet injectors, based on the TSG technology, since 1984. A compact and reliable design of the TSG was developed [8],[9],[10], while different techniques for the formation of cryogenic pellets were investigated, with the aim of improving the mechanical strength of $\mathrm{D}_{2}$ ice to better withstand the huge stress during acceleration. In particular, the "in-situ" pellet formation process was optimized to provide accurate control of deuterium freezing parameters; temperatures need to be carefully controlled during pellet formation under a constant $\mathrm{D}_{2}$ gas pressure, and then smoothly lowered to $\sim 7 \mathrm{~K}$ and kept stable to ensure good resistance of cryogenic projectiles. This was shown to be a key issue for the attainment of launching speeds in excess of $3 \mathrm{~km} / \mathrm{s}$ [11],[12].

In the early 90's a long lasting collaboration between ENEA and Oak Ridge National Laboratory (ORNL), concerning the development of high-speed pellet injectors, was started, with the initial aim of developing the first repeating high-speed device. A facility was assembled at ORNL, combining an existing ORNL piston extruder and an ENEA repeating TSG [13],[14]. Sequences of up to 20 solid $\mathrm{D}_{2}$ pellets (limited by the capacity of the extruder reservoir) were launched with a repetition rate of up to $\sim 1 \mathrm{~Hz}$ and speeds up to $\sim 2.5 \mathrm{~km} / \mathrm{s}$ 
[15],[16],[17],[18]. A component was discovered to be crucial for these achievements; it was a special "spring-loaded" relief valve [19], developed by the ENEA team, placed at the gun breech and capable of suitably tailoring the rising edge of the pressure pulse to prevent pellets from starting to move prematurely (thus producing almost the same effect of increasing the breakaway pressure, which is very low in the case of extruded pellets). Since then, good progress has been achieved on both fronts of solid deuterium extruders, and operation and reliability of two-stage guns. For instance, steady-state extruders, in either single-screw [20] or twinscrew [21],[22] driven configurations, can provide sequences of a potentially unlimited number of pellets. Recently, a comprehensive R\&D program has been proposed by ORNL and ENEA teams, aimed at investigating how far speed limits and repetition rates can be extended, using up to date technologies [23].

Combining once again ORNL and ENEA equipment, a different test facility (fig. 4), originally designed for the Ignitor experiment and named IPI (Ignitor Pellet Injector), has been jointly assembled at ORNL. This pipe-gun injector,

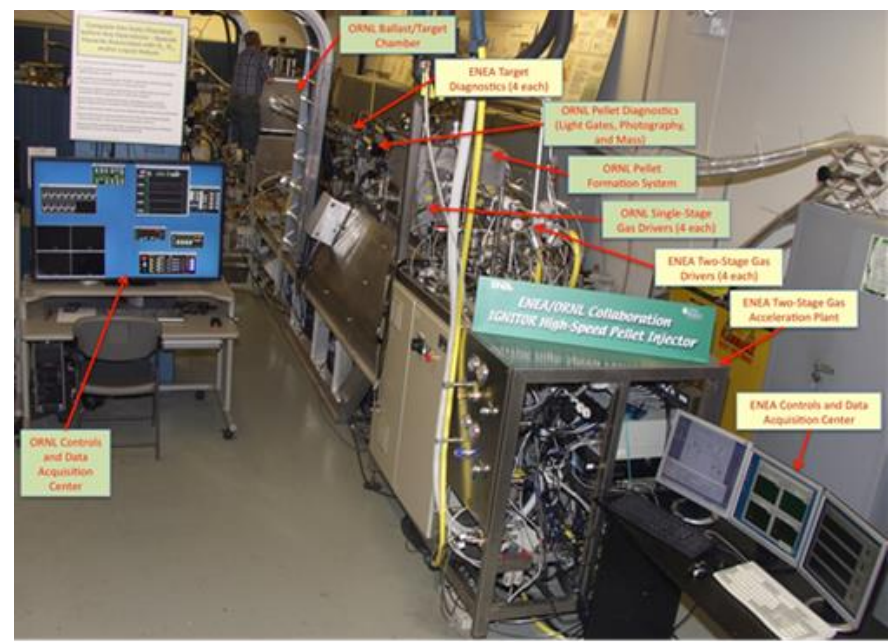

Fig. 4. The ENEA-ORNL high-speed four-barrel pellet injection facility IPI at ORNL

equipped with four barrels $(1.9,2.6,3.2$ and $4.4 \mathrm{~mm}$ internal diameters), was originally designed to launch $\mathrm{D}_{2}$ ice pellets at speeds in the 3 to $4 \mathrm{~km} / \mathrm{s}$ range, using two-stage light-gas guns. The injector features many innovative solutions, such as a cryogen-free cryostat, and a new ENEA propellant gas removal system, that uses fast-closing $(\sim 9 \mathrm{~ms})$ gate valves to eliminate the need of large expansion volumes [24],[25]. An upgraded "magnetic" version of the above mentioned pressure-tailoring relief valve has also been developed by the ENEA team [26]. This device is much more reliable and versatile compared to the previous spring-loaded prototype, eliminating all problems related to the progressive yielding of the spring stiffness (of particular concern for repetitive operation), and allowing to adjust the force acting on the valve shutter by simply varying the electric current flowing in the solenoid. It actually contributes to further improve the reliability of the TSG, and might perhaps enhance the speed performance also in the case of pipe-gun injectors [27].

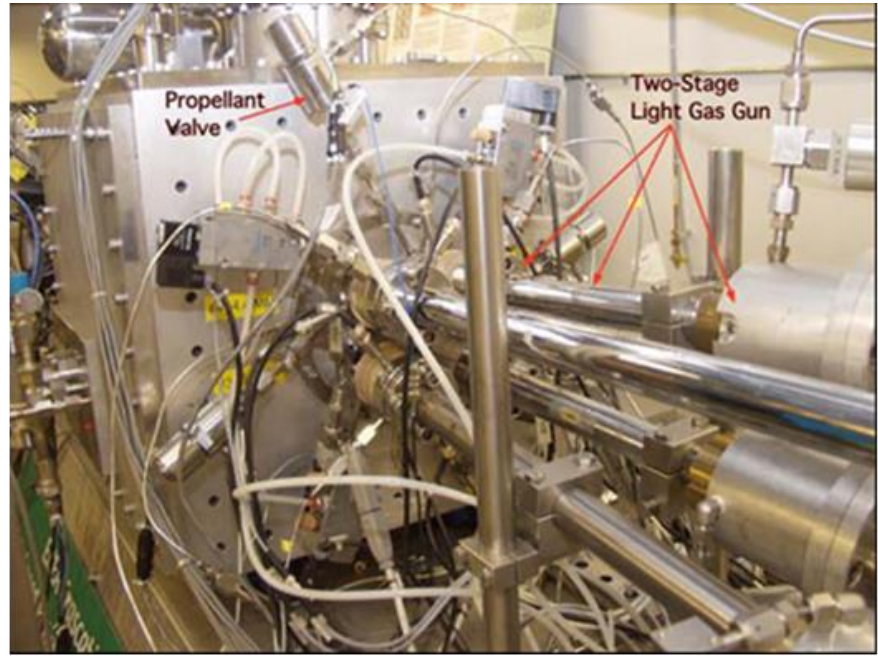

Figure 5 . The new arrangement accommodating both a propellant valve and a two-stage gun on each barrel.

A specific arrangement (fig. 5), that allows accommodating both a single-stage propellant valve and a TSG on each barrel, has also been developed [28], with the aim of providing injection speeds ranging from a few hundred up to a few thousand $\mathrm{m} / \mathrm{s}$. About 200 shots have been performed, alternating single and two-stage gun operation, without any failure. Incidentally, such a configuration might be easily extended, in principle, to accommodate more compact TSG drivers on the single gun-barrel of an injector based on a screw extruder, with the aim of improving the repetition rate. The injection frequency required to maintain a stationary volumeaveraged plasma density of $\sim 10^{20} \mathrm{~m}^{-3}$ in DEMO, is predicted to be less than $\sim 4 \mathrm{~Hz}$, for ITER standard-sized pellets $\left(6 \times 10^{21}\right.$ particles each, corresponding to cylindrical pellets having diameter and length of $5 \mathrm{~mm}$ ) injected from the HFS at speeds in the 300 to $1000 \mathrm{~m} / \mathrm{s}$ range [29]. Accommodating four compact TSG drivers on the same barrel does not seem to be a prohibitive task.

As a further unique feature, the injector located at ORNL can be remotely operated by a control station at ENEA

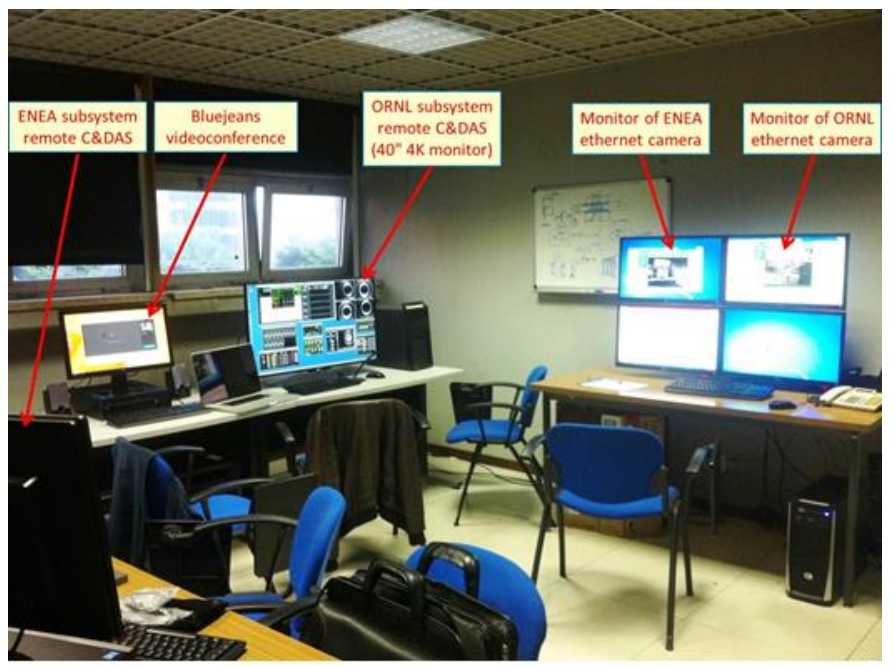

Fig. 6. The IPI remote control station at ENEA Frascati 
Frascati (fig. 6) [27].

So far, preliminary high-speed tests of the IPI have been performed using a Cryomech PT810 two-stage pulse tube cryo-generator, already in use at ORNL, featuring a cooling power of $80 \mathrm{~W} @ 80 \mathrm{~K}$ on the first stage and 14 W @ 20K on the second stage. With this device, the minimum temperatures achieved inside the cryostat were $\sim 100 \mathrm{~K}$ at the thermal radiation shield, and $\sim 10 \mathrm{~K}$ at the pellet freezing zone (nominal $8 \mathrm{~K}$ should be available on the second stage with no thermal load). In these conditions, launching speeds up to 2.6 $\mathrm{km} / \mathrm{s}$ were readily obtained, but pellets were broken above 2 $\mathrm{km} / \mathrm{s}$, perhaps due to the bad quality of deuterium ice as a result of the limited performance of the cryo-cooler, resulting in detrimental temperature oscillations [9]. Nonetheless, within the range of velocities explored so far, test results indicate that the IPI is able to launch pellets at velocities higher than those achieved, for the same value of the pressure peak, with previous two-stage pipe-gun injectors [30], thus substantiating its potential to provide enhanced speed performance. A more powerful pulse tube cryo-cooler (Cryomech PT415) has been procured, and replaced the existing unit with the aim of ameliorating pellet formation parameters and producing better ice quality. This device, featuring a refrigerating power of $40 \mathrm{~W} @ 45 \mathrm{~K}$ on the first stage and 1.5 W@4.2 K on the second (nominal minimum temperature without thermal load is $2.8 \mathrm{~K}$ ), was chosen also for its design, almost similar to that of the PT810, allowing replacement of the existing unit with minimal mechanical adjustments. Preliminary cooling tests with the PT415 showed a significant reduction of the temperatures measured at both the shield $(\sim 50 \mathrm{~K})$ and the freezing region $(\sim 7.5 \mathrm{~K})$. Further minor changes of the cryostat configuration have been planned, to reduce the thermal input toward the freezing zone and achieve better control of the temperature, avoiding oscillations.

\section{SHORT-TERM PROPOSED IMPLEMENTATION PLAN AND FURTHER R\&D PROPOSALS ON A MID-TERM SCALE}

Upon carrying out the minor cryostat modifications mentioned above, this facility could be used, more or less as it is, to explore its potential in terms of high speed performance, and to characterize in these conditions the scatter cone of freeflight pellets. This represents indeed a first important information we need, to assess the feasibility of direct line injection of high-speed pellets from the HFS. In previous experiments, carried out many years ago using high-speed pipe-gun injectors for FTU, the scatter cone of free-flight pellets was carefully characterized, recording their impact position on a target placed $3 \mathrm{~m}$ downstream of the gun muzzle. Our experience is that the angular spread of free-flight trajectories tends to increase, to some extent, when the pellet velocity exceeds $3 \mathrm{~km} / \mathrm{s}$, but within this speed limit it remains rather small. A very large number of pellets was indeed launched (thus attesting the statistical relevance of the results), and all pellets were systematically observed to hit the target well within a circle (centered along the barrel axis) of $3 \mathrm{~cm}$ in diameter [9],[31]. This indicates that, up to $3 \mathrm{~km} / \mathrm{s}$, the scatter cone is expected to have an angle of less than $3 \mathrm{~cm} / 300 \mathrm{~cm}=$ $0.01 \mathrm{rad}\left(0.57^{\circ}\right)$, or about $8 \times 10^{-5}$ sr. To consolidate these earlier data and, hopefully, extend them to higher pellet velocities, it is necessary to have available a high-speed pellet injector. Compared to the option of building a new dedicated system, the possibility of using the existing IPI facility will allow carrying out the proposed experimental program at considerably reduced costs, and on a much shorter timescale..

As a second step, the IPI could then be used to explore the suitability of straight guide tubes to minimize the undesired effects of the scatter cone. This will however require the construction of some specific hardware, and, likely, of suitable diagnostics, to be integrated in the existing injector in order to endow the $4.4 \mathrm{~mm}$ barrel (corresponding to $\mathrm{D}_{2}$ pellets with a content of $\sim 4 \times 10^{21}$ atoms, which is not far from the pellet size considered for DEMO core fueling) with the appropriate equipment. These tests should mainly be devoted to explore the possibility that high-speed pellets can survive inside such a long straight guide tube, with negligible mass and speed losses, and without causing an excessive gas pressure buildup, which are the main detrimental effects usually observed in curved guide tubes when trying to increase the pellet speed. The scatter cone downstream of the guide tube should also be investigated, to assess whether it is affected to any extent by the tube itself, though this seems to be less of concern compared to the other issues listed above.

Due to the many structures surrounding the plasma (bioshield, cryostat, breeding blanket, vacuum vessel), the pellet injector needs indeed to be placed many meters from the plasma. In the absence of a guide tube, the trajectories of freeflight pellets spread out, within the scatter cone, as soon as they escape from the gun muzzle. The longer is the distance that the pellets have to travel to reach the plasma, the larger is the cross section of the apertures they need, to pass through the above mentioned structures, as schematically shown in figure 7(a). Conceivably, a straight guide tube (provided that the pellets can survive and be delivered intact at the downstream end with negligible mass and speed losses) could shift the vertex of the scatter cone downward, from the gun muzzle to the downstream end of the tube, as depicted in figure 7 (b). This would significantly reduce the space

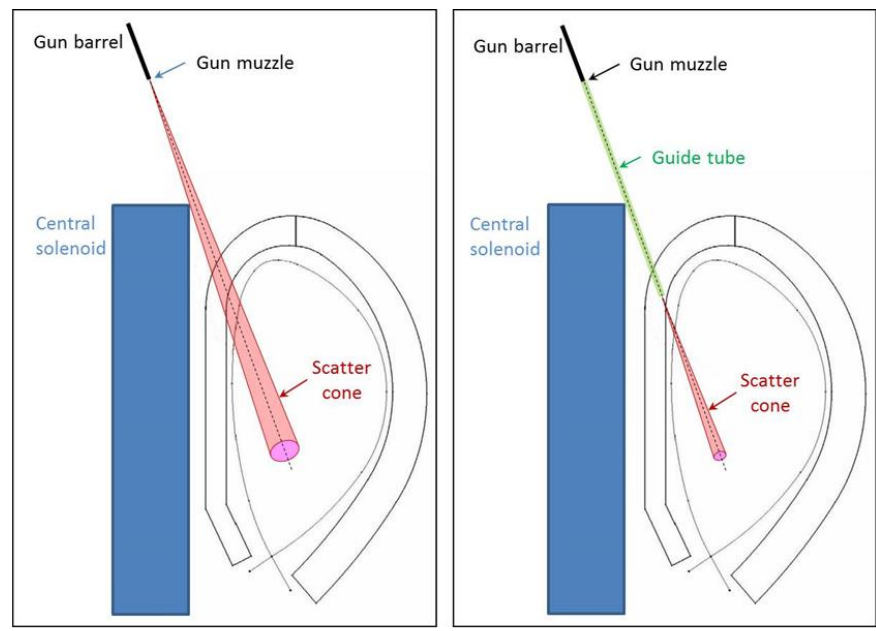

Figure 7. The large cross section of the apertures required by free-flight injection trajectories on penetration of the reactor structures (a), can be significantly reduced using a straight guide tube (b). 
reservation requirements and the impact on the reactor design, almost regardless of how wide the scatter cone is.

Possible alteration of the scatter cone that might be caused by the straight guide tube, can affect to some extent the direction of the trajectories inside the plasma; however, simulations carried out with the HPI2 code, allowing the injection angle to vary by $\pm 2^{\circ}$, indicate that no significant modification of the deposition profile is expected to occur.

\section{DISCUSSION}

According to a commonly accepted conceptual scheme, the pellet trajectory inside a curved guide tube is thought of as a polygonal track, with the pellet bouncing off the wall of the guide tube [2]. If the curvature radius is large enough, we can also imagine that the pellet slides inside the guide along the outboard face of the track contour. In both cases, it is hypothesized to be sufficiently protected by a thin gas cushion, which is ablated from the solid pellet by the Leidenfrost effect, until a critical perpendicular impact force, or a crucial centrifugal force, is reached, causing the expulsion of this protective gas layer from the gap between the pellet and the wall. This immediately causes further gas to be ablated from the solid, and the creation a new protective gas layer. This description of the process may give reason of the observed mass and speed losses, as well as of gas pressure buildup inside the tube. A sufficiently strong impact may also result in breaking the pellet, so it is important, particularly when the pellet travels at relatively high-speeds, to minimize the impact angle and hence the related momentum transfer. As a consequence, the higher the pellet speed, the larger is the curvature radius required to preserve pellet integrity. An empirical scaling law, calibrated on the AUG experiment for cubic shaped pellets [2], is commonly adopted to estimate the maximum speed $V_{i n j}(\mathrm{~m} / \mathrm{s})$ that pellets can withstand, given the curvature radius $R(\mathrm{~m})$ of the guide tube and the pellet size $L$ (m):

$V_{i n j}(m / s)=36.4 \sqrt{\frac{R(m)}{L(m)}}$

However, it is unclear whether this scaling law may be reliably extended to either speeds in excess of $\sim 1 \mathrm{~km} / \mathrm{s}$, or to the pellet sizes required for DEMO; for instance, the quality of $\mathrm{D}_{2}$ ice might be affected, in the case of big pellets, by different freezing conditions. Should this lead to intolerable speed limits, the injection of high-speed pellets from the HFS along "direct line" paths, may represent the only possible alternative. In a straight guide tube, the effects described above for curved tubes should indeed be eliminated, or at least minimized. Centrifugal stress is expected to be completely gone, however pellets might still bounce off the wall, if the size of the guide tube is too large compared to the pellet size, though in this case the impact angle should be very small. Nonetheless, at very high speeds, the impact force might be sufficient to destroy the pellet, despite of the small impact angle. These considerations suggest that the inner size of the guide needs to be optimized, perhaps be taken comparable to the pellet size, to prevent bounce off; the Leidenfrost effect could protect the pellet and minimize friction against the guide wall. A definitive answer to these questions can only be provided, however, by suitable experiments.

In the end, the possibility of bending the guide tube a little bit, compatibly with the required speed performance, should be also explored, since this could in principle increase the number of possible inboard high-speed injection trajectories complying with existing constraints, and also reduce the neutron flux across the guide, compared to the case of a guide tube with a direct line of sight. For pellets travelling at $3 \mathrm{~km} / \mathrm{s}$ and with a particle content of $6 \times 10^{21} \mathrm{D}$ atoms (corresponding to a $\mathrm{D}_{2}$ ice cube having a side length $L$ of $\sim 4.7 \mathrm{~mm}$ ), eq. (1) would predict a minimum curvature radius of $\sim 32 \mathrm{~m}$ to preserve their integrity, thus limiting the potential of such an approach. Probably, the interference with the poloidal coil situated at the top of the machine may lead to bigger problems than the interaction with blanket modules. The underlying problem is that fusion devices are usually designed without accounting for fuelling, which however is of primary relevance. A fusion reactor should be designed and built, with the fuelling system in mind from the beginning and not as an afterthought, by simultaneously designing the poloidal coil and the pellet injection lines, to obtain compatible geometries.

The problem of neutron flux deserves further investigation. Speed performance above $1 \mathrm{~km} / \mathrm{s}$ can only be achieved with pneumatic gas guns (either single- or double-stage devices depending on the required injection velocity), so it will be necessary to pump out the propellant gas before the guide tube penetrates in the machine. This will require some additional space that, in the case of direct line injection, contributes to increase the distance of the injector from the reactor. On the other hand, a direct line guide tube, through which high-speed pellets will be injected into the plasma, will presumably be a rather narrow and long tube, so that the injector will eventually be placed at a distance of several meters from the plasma; the neutron flux across such a path is expected to be dominated by scattered neutrons, whereas, due to the very small solid angle, the contribution of neutrons that can reach the injector end by free-flight is presumably negligible. Therefore, the neutron flux at the injector extremity of the tube might be attenuated by several orders of magnitude by shielding, despite of the direct line of sight, perhaps resulting also in a tolerable neutronic heat load on the cryogenic pellet source. Moreover, if desired, it should be fairly easy to add even more shielding in front of the injector (using for instance borated plastic) to further attenuate the neutron flux. This topic is presently under investigation.

\section{REFERENCES}

[1] B. Pégourié, Ch. Day, A. Frattolillo, F. Koechl, and P.T. Lang, "Physical constraints on the design of the DEMO pellet fueling system," in Proc. of the $43^{\text {rd }}$ EPS Conf. on Plasma Phys., Leuven (B), July 4 - 8, 2016, 
P4.076. [Online]. Available: http://www.euro-fusionscipub.org/wpcontent/uploads/WPTFVCP16_15341_submitted.pdf

[2] P. T. Lang, Ch. Day, E. Fable, Y. Igitkhanov, F. Köchl, R. Mooney, B. Pégourié, B. Ploeckl, R. Wenninger, and H. Zhom, "Considerations on the DEMO pellet fueling system," Fus. Eng. Des. vol. 96-97 pp. 123128, Oct. 2015, 10.1016/j.fusengdes.2015.04.014

[3] A. Frattolillo, F. Bombarda, Chr. Day, P.T. Lang, S. Migliori and B. Pégourié, "An innovative approach for DEMO core fuelling by inboard injection of high-speed pellets," Fus. Eng. Des. 124(2017), 846-849

[4] B. Pégourié, V. Waller, R. J. Dumont, L-G Eriksson, L. Garzotti, A. Géraud, and F. Inbeaux, "Modelling of pellet ablation in additionally heated plasmas," Plasma Phys. Control. Fusion vol. 47 pp. 17-35 (2005) 10.1088/0741-3335/47/1/002

[5] F. Koechl, B. Pégourié, A. Matsuyama, H. Nehme, V. Waller, D. Frigione, L. Garzotti, G. Kamelander, V. Parail and JET EFDA Contributors, Modelling of Pellet Particle Ablation and Deposition: The Hydrogen Pellet Injection code HPI2, EFDA-JET-PR(12)57

[6] B. Pégourié, V. Waller, H. Nehme, L. Garzotti, and A. Géraud, "Homogenization of the pellet ablated material in tokamaks taking into account the $\nabla$ B-induced drift," Nucl. Fusion vol. 47 pp. $44-56$ (2007), 10.1088/0029-5515/47/1/006

[7] R. Wenninger, R. Kembleton, C. Bachmann, W. Biel, T. Bolzonella, S. Ciattaglia, F. Cismondi, M. Coleman, A.J.H. Donné, T. Eich, E. Fable, G. Federici, T. Franke, H. Lux, F. Maviglia, B. Meszaros, T. Pütterich, S. Saarelma, A. Snickers, F. Villone, P. Vincenzi, D. Wolff and H. Zohm, "The physics and technology basis entering European system code studies for DEMO," Nucl. Fusion Vol. 57016011 (2017), 10.1088/0029-5515/57/1/016011

[8] A. Reggiori, R. Carlevaro, G. Riva, G.B. Daminelli, F. Scaramuzzi, A. Frattolillo, L. Martinis, P. Cardoni, and L. Mori, "High-speed pellet injection with a two-stage pneumatic gun," J. Vac. Sci. Technol. A vol. 6 (4), pp. 2556-2558, Jul/Aug 1988, 10.1116/1.575546

[9] A. Reggiori, G. Riva, G.B. Daminelli, A. Frattolillo, L. Martinis, and F. Scaramuzzi, "Solid deuterium pellet injection with a two-stage pneumatic gun,"J. Vac. Sci. Technol. A vol. 7 (3), pp. 959-962, May/Jun $1989,10.1116 / 1.575827$

[10] L. Martinis, F. Scaramuzzi, A. Frattolillo, and S. Migliori, "A new twostage pellet injector for FTU," Proc. of the IEEE/NPSS 13th SOFE, Knoxville (TN), U.S.A., $\quad 1989, \quad$ pp. 1248-1251 10.1109/FUSION.1989.102439

[11] A. Frattolillo, S. Migliori, G. Angelone, M. Baldarelli, C. Domma, F. Scaramuzzi, P. Cardoni, and G. Ronci, " $3.3 \mathrm{~km} / \mathrm{s}$ solid $\mathrm{D}_{2}$ single pellet injector for the Frascati Tokamak Upgrade," Proc. of the IEEE/NPSS 14th SOFE, San Diego (CA) U.S.A., 1991, pp. 721-723 10.1119/FUSION.1191.218746

[12] A. Frattolillo, S. Migliori, G. Angelone, M. Baldarelli, M. Capobianchi, C. Domma, F. Morelli, F. Scaramuzzi, P. Cardoni, G. Ronci, G. Buceti, P. Micozzi, and G. Tonini, "High-speed pellet injectors for the Frascati Tokamak Upgrade," in Fusion Technology 1992 (Proc. of the 17th SOFT), Rome, Italy, Vol. 1, 1992, pp. 505-509, 10.1016/B978-0-44489995-8.50094-1

[13] A. Frattolillo, M. Gasparotto, S. Migliori, F. Scaramuzzi, G. Angelone, M. Baldarelli, G. Ronci, S. K. Combs, S. L. Milora, C. R. Foust, M. J. Gouge, A. Reggiori, G. Riva, R. Carlevaro, and G. B. Daminelli, "Highspeed repetitive pellet injector prototype for magnetic confinement fusion devices," in Fusion Technology 1992 (Proc. Of the 17th SOFT), Rome, Italy, 1992, p. 500-504, 10.1016/B978-0-444-89995-8.50093-X

[14] A. Frattolillo, M. Gasparotto, S. Migliori, F. Scaramuzzi, G. Angelone, M. Baldarelli, M. Capobianchi, C. Domma, G. Ronci, S. K. Combs, S. L. Milora, C. R. Foust, M. J. Gouge, R. Carlevaro, G. B. Daminelli, A.
Reggiori, and G. Riva, "High-speed repetitive pellet injector prototype for magnetic confinement fusion research," IAEA Technical Committee Meeting on Pellet Injection, Jaeri, Naka (Japan), May 10-12 1993, pp. 65-70

[15] S. K. Combs, L. R. Baylor, C. R. Foust, M. J. Gouge, S. L. Milora, A. Frattolillo, M. Gasparotto, S. Migliori, F. Scaramuzzi, G. Angelone, M. Baldarelli, M. Capobianchi, C. Domma, and G. Ronci, "High-speed repetitive pellet injector for plasma fueling of magnetic confinement fusion devices," Proc. of the IEEE/NPSS 15th SOFE, Hyannys (MA), U.S.A., 1993, pp. 48-51. 10.1109/FUSION.1993.518279

[16] A. Frattolillo, S. Migliori, F. Scaramuzzi, M. Capobianchi, C. Domma, G. Ronci, S.,K. Combs, S. L. Milora, and C. R. Foust, "A two-stage pneumatic repeating pellet injector for refuelling magnetically confined plasmas in long-pulse fusion experiments," Proc. of the IEEE/NPSS 16th SOFE, Champaign (IL), U.S.A., Vol. 2, 1995, pp. 1593-1596 10.1109/FUSION.1995.534529

[17] A. Frattolillo, S. Migliori, F. Scaramuzzi, S. K. Combs, L. R. Baylor, C. R. Foust, M. J. Gouge, and S. L. Milora, "High-speed repeating hydrogen pellet injector for long-pulse magnetic confinement fusion experiments," Rev. Sci. Instrum. Vol. 67 (5) May 1996, 1834-1841, 10.1063/1.1146988

[18] A. Frattolillo, S. Migliori, S. K. Combs, and S. L. Milora, "Development of two-stage pneumatic repeating pellet injector for the refueling of longpulse magnetic confinement fusion devices," Fusion Technology Vol. 32, no. 4, Dec. 1997, 601-609

[19] Impulse modelling valve with threshold opening, by S. Migliori and A. Frattolillo, (1996, Aug. 20th). Patent. ITRM950100 (A1) [Online] Available:

https://worldwide.espacenet.com/publicationDetails/biblio?CC=IT\&NR $=$ RM950100\&KC $=\&$ locale $=$ en_ep $\& F T=E \#$

[20] I. Vinyar, A. Geraud, M. Wyman, L. Dequan, A. Lukin, A. Umov, S. Sklobikov and P. Reznichenko, "Pellet injectors developed at Pelin for JET, TAE and HL-2A," Fus. Eng. Des. 86 (2011) 2208-2211

[21] S. J. Meitner, L. R. Baylor, J. J. Carbajo, S. K. Combs, D. T. Fehling, C. R. Foust, M. T. McFee, J. M. McGill, D. A. Rasmussen, R. G. Sitterson, D. W. Sparks and A. L. Qualls, "Development of a Twin-Screw $\mathrm{D}_{2}$ Extruder for the ITER Pellet Injection System," Fus. Sci. Technol., 56:1, 52-56, DOI: 10.13182/FST09-20

[22] S. K. Combs, L. R. Baylor, S. J. Meitner, J. B. O. Coughman, D. A. Rasmussen and S. Maruyama, "Overview of recent developments in pellet injection for ITER,” Fus. Eng. Des. 87 (2012), 634-640

[23] F. Bombarda, A. Frattolillo, S. Migliori, S. Podda, F. Iannone, G. D'Elia, F. Gravanti, L. Baylor and S. K. Combs, "State of the art and perspective of high-speed pellet injection technology," Fus. Eng. Des. 124 (2017), 797-800

[24] A. Frattolillo, L. R. Baylor, F. Bombarda, J. B. O. Caughman, S. K. Combs, B. Coppi, D. T. Feheling, C. R. Foust, J. M. McGill, S. Migliori, G. Roveta, and J. Thomas, "Peaked density profiles and high speed pellet injection for the Ignitor burning plasma experiment," Proc. of the 33rd EPS Conf. on Plasma Phys. Rome, Italy, ECA Vol. 301, P-4.185 (2006) Eps 2006. 3: 1800-1803

[25] A. Frattolillo, S. Migliori, F. Bombarda, S. K. Combs, L. R. Baylor, C. R. Foust, and G. Roveta, "The compact, four barrels high speed pellet injector for the Ignitor experiment," Proc. of the 22nd IEEE/NPSS SOFE, Albuquerque (NM), U.S.A., 2007, 10.1109/FUSION.2007.4337902

[26] S. Migliori, A. Frattolillo, S. K. Combs, L. R. Baylor, G. Roveta, F. Bombarda, C. R. Foust, D. T. Fehling, J. M. McGill, J. B. O. Caughman, and J. C. Thomas, "The compact, multiple barrel high speed pellet injector for the Ignitor experiment," Proc. of the 21st IEEE/NPSS SOFE, 
Knoxville (TN), U.S.A., 2005 10.1109/FUSION2005.252921

[27] A. Frattolillo, S. Migliori, S. Podda, F. Bombarda, G. D’Elia, F. Poggi, S. K. Combs, C. R. Foust, S. J. Meitner, D. T. Fehling, L. R. Baylor and G. Roveta, "Progress with the ENEA-ORNL high-speed four barrels pellet injector," Proc. of the 42nd EPS Conf. on Plasma Phys., Lisbon (P), ECA Vol. 39E, P2.155 (2015), ISBN 2-914771-98-3

[28] A. Frattolillo, F. Bombarda, S. Migliori, S. Podda, M. Capobianchi, G. Ronci, L. R. Baylor, S. K. Combs, C. R. Foust, S. Meitner, D. Fehling, B. Coppi, and G. Roveta, "Work in progress with the high speed pellet injector for Ignitor," Proc. of the 37th EPS Conf. on Plasma Phys., Dublin, Ireland, ECA Vol. 34A, P-5.153 (2010), ISBN 9781622763313

[29] P. Vincenzi, F. Koechl, L. Garzotti, D. B. King, E. Tindale, T. Bolzonella, P. T. Lang, B. Pegourié, M. Romanelli and R. Wenninger, "Fuelling and density control for DEMO," Nucl. Fusion 55 (2015) 113028

[30] A. Frattolillo, F. Bombarda, S. Migliori, S. Podda, M. Capobianchi, B. Coppi, S. K. Combs, C. R. Foust, S. Meitner, D. Fehling, J. McGill, L. R. Baylor, S. L. Milora, and G. Roveta, "Advances on the high speed Ignitor Pellet Injector (IPI)," Proc. of the 24th IEEE/NPSS SOFE, Chicago (IL), 2011 10.1109/SOFE2011.6052237

[31] A. Frattolillo, S. Migliori, F. Scaramuzzi, G. Angelone, M. Baldarelli, M. Capobianchi, P. Cardoni, c. Domma, L. Mori, and G. Ronci, "Highspeed multishot pellet injector prototype for the Frascati Tokamak Upgrade," Rev. Sci. Instrum. Vol. 69 (7), July 1998, pp. 2675-2680 10.1063/1.1148997 